UJBM, Vol. 2, No. 1, January - June 2003, pp 67-67

ISSN 0975-3311

https:/ / doi.org/ 10.12725/ ujbm.2.6

\title{
WOMEN AND BIOTECHNOLOGY
}

\author{
Dr. Seema Prakash* and Dr. Latha Sivaram**
}
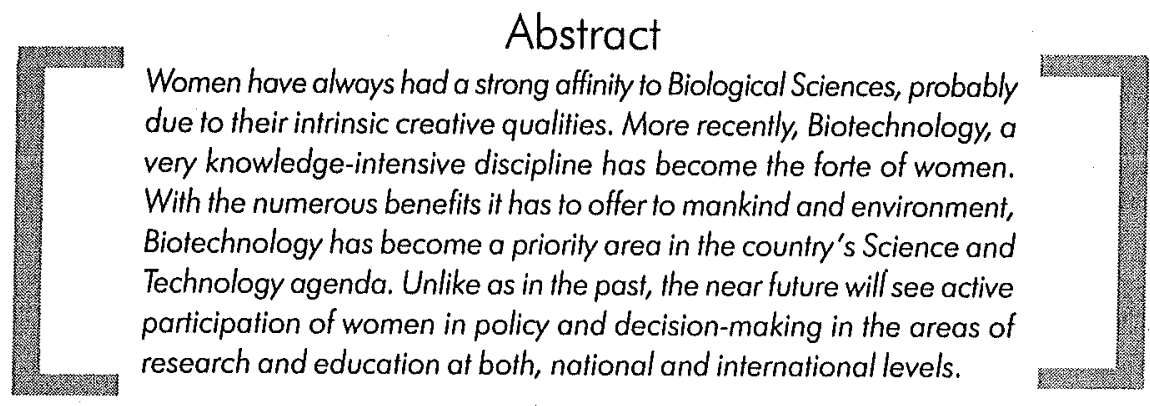

\section{Introduction}

The science of Biotechnology is as old as the human civilization itself. On the other hand, it is the most recent and still evolving science. The first steps in Biotechnology were made when the first wines and cheese and pancakes were made. For thousands of years moulds and bacteria have been used to make fermented foods, to make beer, wine and bread and to preserve foods by furning milk into cheese and yogurt. Biotechnology reached the pinnacle when the human genome was first unveiled. The recent advances in Biotechnology have resulted in research and development

\footnotetext{
* Managing Director of In Vitro International Private Limited and Founder Director of Biotechnology and Eco-Development Research Foundation, Bangalore.

** Manager - Scientific Communications at In Vitro International Private Limited, Bangalore.
} 
that may lead to commercialization of products which can dramatically improve human and animal health, food supply and the quality of the environment. The discipline cuts across many of the already existing disciplines such as Biochemistry, Molecular Biology, Microbiology, Plant Breeding and Computer Science. Biotechnology finds its application in many fields such as Agriculture, Forestry, Energy Production, Human Health and Diagnostics, Food and Nutritional Security. There is hardly any area in which Biotechnology does not find an application.

Women all over the world, despite many barriers, have participated in unraveling the secrets of nature ever since the dawn of civilization. Though they form only $7.7 \%$ of the work force in Science and Technology, they have maximum representation viz. $88 \%$ in the Natural and Medical Sciences and a negligible 3\% in Engineering and Technology. Biotechnology like Information Technology is knowledge intensive and offers a tremendous opportunity to involve women at different levels in society. In the words of Rajni Rani, a scientist at the National Institute of Immunology (NII), and the creator of "Leprovac", the first successful vaccine against leprosy, "women are naturally more methodical and precise - these qualities are handy for the painstaking research that Biotechnology demands". Women also have a better sense of the practical. They are more comfortable working on projects, which directly contribute, to human well-being. The traditional male neglect of the Biological Sciences has also helped women carve for themselves a niche in the field of Biotechnology.

\section{Overview}

The progress of the developing world, good as it is in terms of accomplishments for many countries, would have presented a more positive picture if so many countries did not succumb to severe inequalities - between men and women, rich and poor, and urban and rural areas. Male-female differentials have caused a lopsided development. During the 1960s, 1970s and 1980s, women did share in the scientific and technological progress taking place in many developing societies, but in a number of important respects, life did not improve for them as fast as it did for men. Women were unequally represented in science and their career progression was not comparable to their male colleagues. The situation improved with the growing awareness of the huge untapped economic potential that women represented and the problems faced by women in Science, Engineering and Technology (SET). Much of the groundswell behind the debate on the small numbers of women in science was sparked by a 1997 study of research funding by the Swedish Medical Research Council (MRC). The study discovered gender bias in the way in which research awards were conferred, a finding that startled the scientific community, as it was the first clear evidence of discrimination. The study concluded that women had to be 
about 2.2 times more productive than their male counterparts to be as successful in securing financial support. The study galvanized many other institutions into action, and in the following years studies on gender bias in funding mechanisms were initiated in the UK, Denmark and Finland. A case study was conducted in one of the largest commercial Biotechnology laboratories in the world, Twyford Plant Laboratories Inc., USA (Table 1). This laboratory produces 100,000 plants a day and 40 million plants a year. For this, 291 women are employed. Hence, for the industry where the potential demand is 16 trillion, the number of women, who could be potentially employed, would be approximately 2.5 billion! (Prakash, 2001).

Table 1. Ratio of women and men working in Twyford Plant Laboratories, Inc.

\begin{tabular}{|l|c|c|c|}
\hline \multicolumn{1}{|c|}{ Designation } & No. of women & No. of men & $\begin{array}{c}\text { \% increases of women } \\
\text { over men }\end{array}$ \\
\hline Executive Managers & 3 & 2 & 50 \\
\hline Research Managers & 2 & 1 & 50 \\
\hline Managers & 8 & 5 & 60 \\
\hline Supervisors & 18 & 5 & 260 \\
\hline Technicians & 260 & 40 & 550 \\
\hline
\end{tabular}

\section{Employment Opportunities for Women in the Biotechnology Industry: The Indian Perspective}

Indian women, both in the urban and rural sectors play a vital role in ensuring healthy, safe, and abundant supply of food. They constitute $80 \%$ of the work force in India's agriculture. The rural women, small farmers, laborers, and entrepreneurs help produce most of the food, create many of the jobs, and manage most of the country's natural resources. Despite these contributions, thousands of rural women in India live below the poverty level, struggling to survive with scarce resources and little training or education. Rural women do not have the mobility to take advantage of better employment opportunities in the urban areas. In the urban sectors, women still have to negotiate major obstacles if they are to be promoled as senior scientists or managers. A high proportion of women scientists remain severely underrepresented in the senior scientific and management positions, which remain largely the men's domain. Thus, on one hand, the urban women have limited influence on the research agenda, and on the other, the rural women although greater in numbers, 
have no influence over the agricultural technology developed by the formal research sector. Besides the above-mentioned factors, some of the obstacles, which prevent women from full participation in research activities, include:

- Gender segregation in education and training, gender stereotypes in culture and society and their influence on parents and girls' attitudes and expectations.

- Unbalanced distribution of domestic responsibilities (for a woman scientist, family and job are offen mutually exclusive alternatives).

- Lack of scientific multidisciplinary culture in the educational curricula.

Efforts must, therefore, be made to overcome the various hurdles in the path of women's careers in the field of Biotechnology. Some of them are as follows:

- Policies to throw open the field of Biotechnology must be adopted, including gender-neutral selection committees.

- Exclusion (explicit and implicit) must be eliminated, as well as intolerance in all its forms.

- The authorities, administration and management must stop the gender brain drain by learning to care about the future of women in Biotechnological careers.

- Family-friendly working conditions must be offered, including social benefits (eg. Tax allowances for child-care costs), so that Biotechnological careers are compatible with family responsibilities.

- Ongoing programmes of education and training, especially for women facing the challenge of renewing their professional activity after a break must be implemented.

- Women need to be able to obtain academic recognition and funding which are necessary to achieve positions of responsibility.

What is needed is to create new opportunities and raise international awareness of the contributions of women to rural development and production agriculture. The highly qualified but relatively cheap work force gives the Indian women an added commercial advantage. Women have to be progressively aggressive in a country like India where science needs to be pushed and $80 \%$ of science is supported by the government.

The main objective in the present circumstances should be strengthening the role of women in the development process and promoting their representation in the scientific and technological leadership. The other objectives to be considered are: 
- To strengthen research efforts and training opportunities of young women scientists.

- To survey and analyze the status and prospects of women in science and technology.

- To promote the recognition of the scientific and technological achievements of women.

- To improve the access to educational and training opportunities for women in science and technology.

- To increase the scientific productivity and efficiency of women scientists.

- To promote collaboration and communication among women scientists and technologists with the international scientific community as a whole.

- To promote their participation in the decision-making processes, both at national and international levels.

- To encourage other international organizations to increase their activities concerned with promoting the role of women in science and technology.

Realizing the potential economic benefits of involving women in the field of Biotechnology, a number of biotechnological strategies have been launched by the Indian government. One of the world's most renowned agricultural scientists, Prof. M.S. Swaminathan, helped draw up the local policy for the unique Women's Biotechnology Park at Chennai in the Southern state of Tamil Nadu. The Park is an example of the lab-to-land efforts in Biotechnology using woman power. The Park would act as a joint venture enterprise where individual entrepreneurs would be shareholders with the Park providing the infrastructure and selecting appropriate biotechnologies for them. Thus it will foster the technological and economic empowerment of women. The Department of Biotechnology, a Government of India organization, has recently launched a series of "Biotechnology Programmes for Women" in order to speed up the process of rural development, where women biotechnologists can be readily absorbed. The Indian Finance Minister announced in Budget 2002 that 100 scholarships would be given to women who would like to return to either study or to research activities.

\section{Conclusion}

After India's soffware revolution, Biotechnology is described as the next best thing to hit the country. Multinational and Indian research companies are investing heavily 
in industry, encouraged by Biotechnology-friendly policies. Both politicians and policy makers believe that besides creating wealth, growth in Biotechnology will also bring medical and ecological breakthroughs. The Indian economy is very much dependent on agriculture. Plant Biotechnology can increase the self-sufficiency of farmers, thus ensuring more and better food for their families and communities. It will result in the production of more suitable farm animals and crop plants as well as improved food and food processing procedures. In a broader sense, Biotechnology holds the promise of new and additional breakthroughs in the fields of medicine, food agricultural products, energy and environmental cleanup. The world will see a revolution in all of these industries in the recent future, thanks to Biotechnology. Biotechnology will give mankind the potential to treat previously incurable genetic diseases and will also provide better and healthier food products, improved, nontoxic pesticides and herbicides. It also holds the promise to enhance the staple crops that provide nourishment in developing countries like India.

Significant progress was achieved during the 1990s in translating the goal of equal opportunities for all into a reality. Equality of opportunities forms part of the essential fabric of human rights and responsibilities in the global development of society. With the growing awareness of the under-representation of women in the scientific community and the need for new strategies to be put into place, several policies have been introduced, including quantitative objectives, new administrative structures and more recently, positive action. In higher education, government and industry, it is clear that it is imperative for equal opportunities and female-friendly policies to be in place to produce the highly desirable 'level playing field'.

Women have been contributing immensely to the conservation of our biodiversity through conventional methods and more recently with the help of biotechnology. On the other hand, the impact of Biotechnology has also been very positive on women's lives (the impressive participation of women in Science and Technology since the 1970s has been possible, thanks to among other things, the innovations in family planning techniques and to technological advances). Women especially in the rural sectors have great strengths, which must be capitalized upon. Thus, Biotechnology is an important tool that can empower women both in the developed and in the developing world. In the words of Naomi Oreskes, historian of science, "the question is not why there haven't been more women in science; the question is rather why we have not heard more about them". Delivering the International Women's day lecture on "Role of Women Scientists and Technologists in National Development, Dr. Manju Sharma, Secretary, Department of Biotechnology rightly 
said that women scientists will be able to give science a fresh perspective and new dimension because they think different from the way men have been thinking in the field. And science thrives on new ideas.

\section{Reference}

Prakash S. 2001. Role of Women in Biotechnology and Rural Development. Seminar on Modern Trends in Biotechnology and Sustainable Rural Development, organized by NISIET (National Institute of Small Industry Extension Training) and Dr. Swaminathan Research Foundation, Hyderabad. July $20^{\text {th }}$ and $21^{\text {st }}$. 